\title{
Optimización de la técnica diafanización y tinción de Piovesana (2014), aplicada para el pez Gymnocorymbus ternetzi
}

\author{
Romero Oliva Oscar Jesús ${ }^{a^{*}}$, Katia Adriana González Rodríguez ${ }^{\text {b }}$ \\ a Estudiante de la Licenciatura en Biología, Instituto de Ciencias Básicas e Ingeniería, Universidad Autónoma del Estado de \\ Hidalgo, México. \\ ${ }^{\text {b }}$ Profesora investigadora, Área Académica de Biología, Instituto de Ciencias Básicas e Ingeniería, Universidad Autónoma del \\ Estado de Hidalgo, México.
}

\section{Resumen}

La diafanización es una técnica histológica que tiene como principal finalidad aclarar los tejidos blandos de un organismo, lo que permite observar tejidos óseos y cartilaginosos. Se emplean diversas sustancias químicas así como colorantes específicos para teñir específicamente hueso y cartílago. No existen protocolos estandarizados por especie, ya que se generaliza por grandes grupos, siendo el de grupo de los peces uno de los menos definidos. En este trabajo se desarrolló una modificación de la técnica de diafanización y tinción ósea para el pez monja (Gymnocorymbus ternetzi), con el fin de optimizar el tiempo y los costos del proceso, ya que puede ser aplicado en peces de características similares.

Palabras clave: diafanización, rojo de alizarina, Gymnocorymbus ternetzi.

\section{Introducción}

La Real Academia Española define la palabra 'diáfano' como un cuerpo que deja pasar la luz a través del mismo casi en su totalidad. Dicho de un espacio que está despejado, o que carece de obstáculos o separaciones. Igualmente lo define como 'algo que se percibe bien' o 'algo claro'. Un sinónimo de la palabra diáfano es transparente. Por ello la palabra 'diafanización' puede entenderse como transparentación o aclaramiento.

Fuera de la semántica y dentro de la biología, la diafanización es una técnica histológica que se realiza mediante la combinación sucesiva de sustancias químicas, de las cuales destaca el hidróxido de potasio $(\mathrm{KOH})$, debido a su actividad corrosiva que permite aclarar a los tejidos blandos. Tejidos duros como hueso y cartílago no se ven afectados, lo cual resulta favorable para el estudio de los mismos sin realizar disecciones anatómicas.

Asimismo, la diafanización es empleada para establecer centros de osificación de embriones y fetos de animales y humanos (Rivera-Cardona et al., 2015) y para realizar comparaciones de las características óseas de distintas especies. Existen diferentes tipos de métodos para diafanizar y teñir organismos, sin embargo la mayoría comparten el mismo fundamento, basado en tres etapas: fijación, transparentación (diafanización) y tinción específica (Figura 1).

La fijación del ejemplar se realiza para mantener a las células intactas, buscando inactivar las reacciones enzimáticas celulares, impidiendo que se presente una autolisis y, por tanto, una degradación post mortem del organismo (Coronado,

*Autor en correspondencia:

Correo electrónico: oromerooliva@gmail.com
2014). Los reactivos esenciales para este paso son: alcohol y formol.

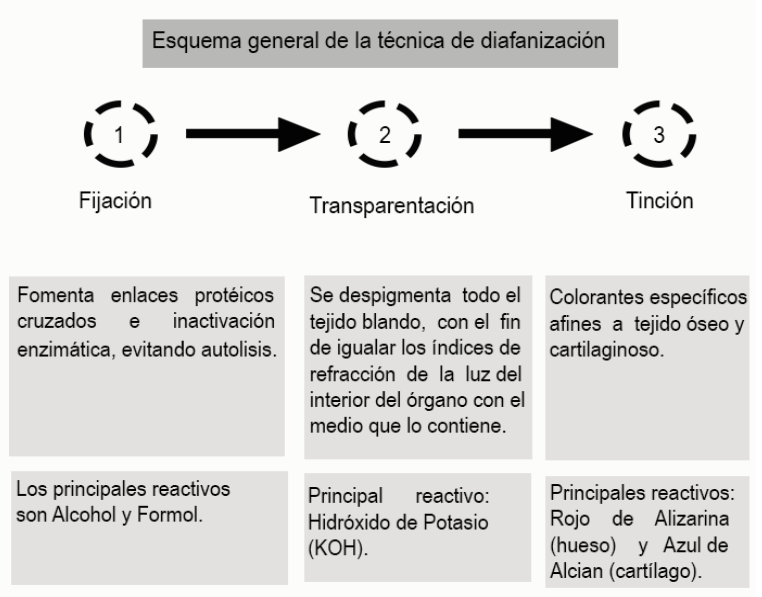

Figura 1. Esquema general de la técnica de diafanización con tinción ósea y cartilaginosa. (Modificado de Dawson, 1926).

La transparentación se lleva a cabo para visualizar y analizar la estructura ósea y cartilaginosa, se transparenta todo el tejido blando, en este proceso se igualan los índices de refracción de la luz del interior del órgano con el medio que lo contiene (Concha, 2006). El reactivo fundamental es el hidróxido de potasio $(\mathrm{KOH})$, debido a que es miscible y corrosivo. Por último, la tinción ósea y cartilaginosa se da por colorantes específicos que son rojo de alizarina y azul de alcián respectivamente. 
Preservar piezas anatómicas diafanizadas es importante para complementar la investigación y el aprendizaje teórico en ciencias biológicas y de la salud, ya que son elementos que ayudan al entendimiento de la anatomía interna de los organismos.

Este trabajo surgió por la necesidad de encontrar técnicas de diafanización en peces, optimizadas en tiempo y costos. Las cuales estén al alcance de todos los estudiantes. De igual manera se realizó para implementar colecciones de docencia en la Universidad Autónoma del Estado de Hidalgo. Debido a que no se logró conseguir el colorante azul de alcián para teñir cartílago, en este protocolo sólo se experimentó con el rojo de alizarina para teñir el tejido óseo.

\subsection{Antecedentes}

La técnica de diafanización fue descrita por Mall (1902) en embriones humanos como una técnica alternativa para el estudio de los centros de osificación. Posteriormente, en investigaciones sobre el desarrollo de miembros torácicos y pelvianos de ratas albinas, Dawson (1926), introdujo el empleo del rojo alizarina para colorear selectivamente el tejido óseo.

Mc Green (1952), trabajó igualmente con ratones con el fin de mostrar la presencia de tejido óseo en tempranas etapas embrionarias. Randle (1969), diseñó una secuencia de procesamiento en masa de ejemplares para analizar el sistema óseo, comenzando a realizar inferencias sobre posibles aplicaciones de la técnica para el estudio de teratogénesis.

Siete años después se implementó una técnica con tinción doble para contrastar los tejidos óseos y cartilaginosos durante el desarrollo embrionario (Inouye, 1976).

Una técnica de procesamiento masivo de organismos con fines de estudios teratogénicos fue planteada un año después por Tipton y Burt (1977). Más tarde se implementó una técnica de diafanización y doble tinción para diferenciar el tejido óseo del tejido cartilaginoso durante el desarrollo embrionario de Rattus norvegicus (Whitaker y Dix, 1979).

Meses después se publicó una adaptación de la técnica de diafanización y doble tinción de Inouye en embriones de ratón (McLeod, 1980).

Taylor y Van Dyke (1985), describieron un protocolo optimizado en peces para la doble tinción simultánea del tejido cartilaginoso con azul alcián y del tejido óseo con rojo alizarina. Para el año de 1994, usando como biomodelos a roedores, se implementó una técnica de diafanización y doble tinción para diferenciar el tejido óseo del tejido cartilaginoso durante el desarrollo embrionario (Webb y Byrd, 1994). En el segundo milenio, la técnica de diafanización se comenzó a utilizar en anatomía comparada, describiendo el sistema esquelético (cartílago y hueso) en dos especies de mamíferos (ratón y murciélago) (Cortés, 2009).

Tilotta Françoise, Lazaroo Bernard, Laujac M y Gaudy J, del Instituto de Anatomía de la Universidad de Saints-Pères, y la Universidad Descartes de París-Francia, realizaron la investigación titulada: "Estudio de la vascularización de la aurícula mediante disección y diafanización", en la que parten de afirmar que el proceso de vascularización de la oreja está mal documentado. Su objetivo fue describir la distribución arterial, usando dos técnicas: diafanización y la disección anatómica (Tilotta, 2009).

En este protocolo solamente fueron teñidos los huesos con rojo de alizarina, descartando la tinción cartilaginosa con azul de alcián, debido que dicho reactivo no se encontraba disponible en los laboratorios del Instituto de Ciencias Básicas e Ingeniería (UAEH).

\section{Principios histoquímicos de la técnica}

El rojo alizarina (Figura 2) es un colorante sintético, soluble en agua, derivado de la antroquinona (compuesto orgánico que se encuentra naturalmente en algunas plantas, hongos, insectos $\mathrm{y}$ minerales).<smiles>O=C1c2ccccc2C(=O)c2c1ccc(O)c2O</smiles>

Figura 2. Fórmula estructural del rojo alizarina, tomada de: http://www.plantasyhongos.es/herbarium/htm/Rubia tinctorum.htm

La alizarina tiene afinidad hacia el tejido óseo, debido a la unión con el calcio de los huesos. Proceso que se da por quelación de una molécula de calcio mediante dos moléculas de alizarina (Kiernan, 1990). Las moléculas de oxígeno de los grupos quinona y fenol de la alizarina, se comportan como dadores de electrones, estableciendo así dos anillos estables con el calcio. El proceso de quelación (Figura 3) puede ocurrir con otros cationes divalentes (magnesio o hierro) pero debido a la baja concentración de los mismos en comparación con los iones de calcio en el tejido óseo, no interfieren en la especificidad de la tinción (Piovesana, 2014).



Figura 3. Reacción de quelación propuesta por Kiernan (1990). Tomado y modificado de Piovesana, et al. (2014) 
Es necesario enfatizar que el calcio del tejido óseo se solubiliza a $\mathrm{pH}$ ácido, perdiendo así iones calcio, por lo cual resulta conveniente preparar la solución de rojo alizarina a un $\mathrm{pH}$ alcalino, con el fin de evitar la descalcificación en el hueso.

\section{Variantes comunes del proceso}

Actualmente, el procedimiento para la diafanización más conocido es la técnica de Dawson-Schultze. La cual tarda más tiempo en generar resultados que las técnicas de Dawson (1926) y de Inouye (1976), debido a que, la concentración del hidróxido de potasio es menor (Villegas et al., 2012).

De acuerdo con Coronado (2014), el proceso de la técnica de diafanización con tinción de Dawon-Schultze comienza con la fijación de la muestra en formol al 10\%, para después teñir los centros de osificación con rojo de alizarina ( 0.1 gramos para organismos pequeños). Posteriormente, la fase de diafanización comienza con la inmersión del ejemplar en una solución de $\mathrm{KOH}$ al $10 \%$ + glicerina pura, en una proporción de 75:25 respectivamente, por un periodo de 5 días.

Para continuar, se preparan dos soluciones, la primera con 65 $\mathrm{ml}$ de agua $\left(\mathrm{H}_{2} \mathrm{O}\right)+65 \mathrm{mg}$ de hidróxido de potasio $(\mathrm{KOH})+$ $35 \mathrm{ml}$ de glicerina pura. La segunda con $50 \mathrm{ml}$ de agua $\left(\mathrm{H}_{2} \mathrm{O}\right)$ $+1 \mathrm{~g}$ hidróxido de potasio $(\mathrm{KOH})+50 \mathrm{ml}$ de glicerina pura. El ejemplar se sumerge en la primera solución por un periodo de 3 días, y en la segunda solución por 2 días. Finalmente se traspasa a una solución de $100 \%$ de glicerina.

Si en esta etapa la muestra no se torna transparente, se puede volver a los pasos anteriores. Por lo general se requiere cambiar varias veces la solución en glicerina pura hasta obtener una transparencia adecuada.

Otro proceso es el de Concha (2006), en el cual se fija la muestra en formol al $10 \%$, se agrega $0.5 \mathrm{~g}$ de rojo de alizarina para teñir los centros de osificación, y después se diafaniza siguiendo el esquema: inmersión del ejemplar en una solución de hidróxido de potasio al $2 \%$ o $3 \%$.

Finalmente se recambian los ejemplares en un grupo de tres soluciones:

A) $75 \mathrm{ml}$ de agua $+150 \mathrm{mg}$ de hidróxido de potasio +25 $\mathrm{ml}$ de glicerina.

B) $50 \mathrm{ml}$ de agua $+100 \mathrm{mg}$ de hidróxido de potasio +50 $\mathrm{ml}$ de glicerina.

C) $25 \mathrm{ml}$ de agua $+50 \mathrm{mg}$ de hidróxido de potasio +75 $\mathrm{ml}$ de glicerina.

Los periodos de tiempo van aproximadamente de dos días por solución; sin embargo, dependen directamente de la observación de resultados deseados.

\subsection{Método de diafanización en peces (Piovesana, 2014)}

- Fijación en formol tamponado al $10 \%$, de 24 a 72 horas.

- Transferencia a etanol al $70 \%$ hasta que los tejidos estén pálidos.

- Coloración del cartílago con solución ácida azul de alcián por 30 minutos.

- Limpieza con agua destilada hasta eliminar excesos del colorante.

- Neutralización con etanol absoluto por tres días.

- Maceración con hidróxido de potasio en concentraciones de 1\%, 3\% o 5\% (dependiendo el tamaño del organismo) por un periodo de 3 a 12 días (hasta que se observen a contra luz las estructuras anatómicas internas).

- Tinción ósea con rojo de alizarina $(0.01 \mathrm{~g}$ en $100 \mathrm{ml}$ de $\mathrm{KOH})$ por 30 minutos.

- Transparentación con solución de Mall $(79 \mathrm{ml}$ de agua destilada $+20 \mathrm{ml}$ de glicerina $+1 \mathrm{~g}$ de $\mathrm{KOH}+$ $50 \mu \mathrm{l} \mathrm{de} \mathrm{H}_{2} \mathrm{O}_{2}$ ) por tiempo indefinido hasta lograr resultados deseados.

- Preservación del ejemplar con glicerina pura.

\section{Protocolo de diafanización aplicado para} Gymnocorymbus ternetzi: Métodos, materiales y costos

Los métodos de diafanización utilizados en peces son variados, por ejemplo para Dawson (1926), Inouye (1976) o Coronado (2014), la elección de alguno de estos métodos depende en gran medida del tamaño y características propias del pez, así como de los recursos disponibles. Con base en lo anterior, se usó al pez monja (Gymnocorymbus ternetzi) por ser un organismo común dentro de la acuariofilia, y por ser de fácil obtención en acuarios locales.

El método empleado para la diafanización de los ejemplares de G. ternetzi, se basa en el propuesto por Piovesana (2014), pero con modificaciones en las concentraciones de los reactivos y en los tiempos de exposición, para optimizar los resultados. El proceso se llevó a cabo con el método heurístico de ensayo y error con diez ejemplares, para obtener las concentraciones exactas. El protocolo de divide en cinco fases:

\subsection{Primera fase}

Se aplicó eutanasia al organismo, no se le retiraron las escamas ni se alteró estructuralmente de ninguna manera (Figura 4). 


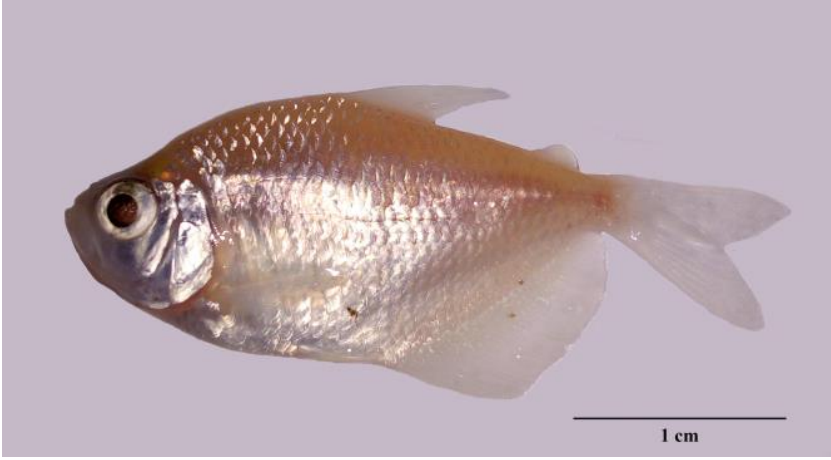

Figura 4. Gymnocorymbus ternetzi minutos después de la eutanasia.

Posteriormente el ejemplar se sumergió en $25 \mathrm{ml}$ de alcohol al $70 \%$ por 40 horas para que se llevara a cabo la deshidratación tisular (Figura 5).

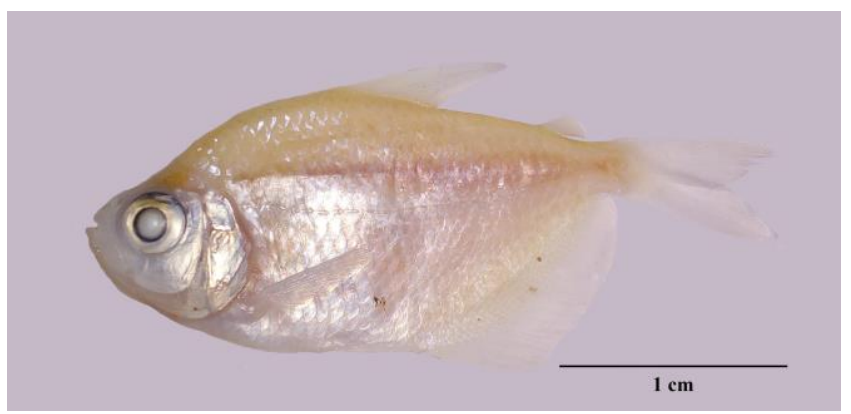

Figura 5. Gymnocorymbus ternetzi al concluir la primera fase. Se aprecia un color más claro debido a la deshidratación tisular.

\subsection{Segunda fase}

Se colocó al ejemplar en $100 \mathrm{ml}$ de agua destilada con 2 gramos de hidróxido de potasio $(\mathrm{KOH})$ por 50 horas para lograr la despigmentación total (Figura 6).

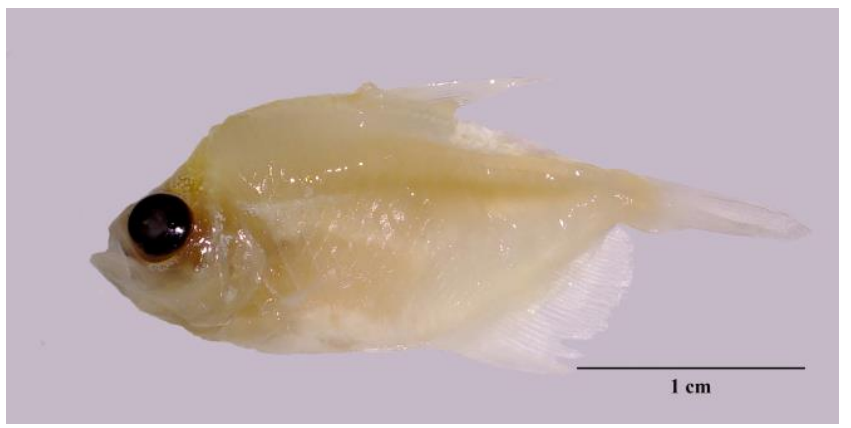

Figura 6. Gymnocorymbus ternetzi al término de la segunda fase. El espécimen presenta despigmentación total.

\subsection{Tercera fase}

El ejemplar se trasladó a otra solución compuesta de $100 \mathrm{ml}$ de agua destilada con 0.5 gr de hidróxido de potasio y 0.8 gramos de rojo de alizarina, por un total de 20 horas (Figura 7). Se lavó el exceso de colorante con agua y posteriormente se neutralizó con alcohol al $70 \%$ por un lapso de 2 horas.

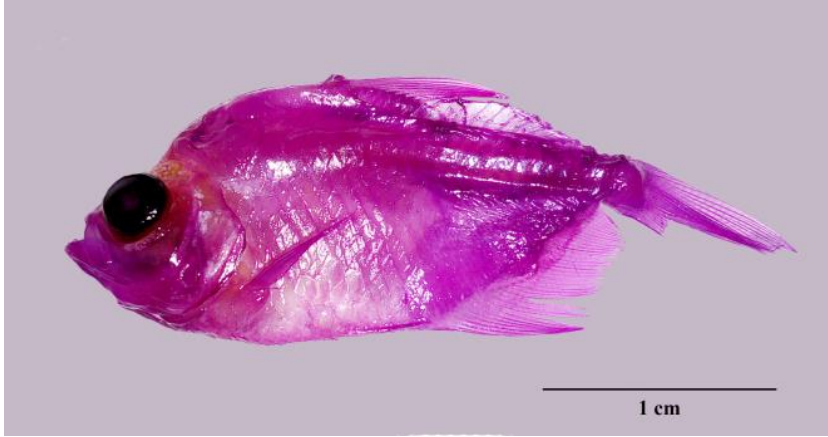

Figura 7. Gymnocorymbus ternetzi después de la tercera fase.

\subsection{Cuarta fase}

El pez fue sumergido en solución de Mall, la cual se preparó con cuatro reactivos en las siguientes concentraciones:

- $\quad 40 \mathrm{ml}$ de agua destilada

- $12 \mathrm{ml}$ de glicerina

- $500 \mathrm{mg}$ de hidróxido de potasio $(\mathrm{KOH})$

- $1 \mathrm{ml}$ de agua oxigenada $\left(\mathrm{H}_{2} \mathrm{O}_{2}\right)$

Se mantuvo dentro de la solución por un lapso de 3 días.

\subsection{Quinta fase}

Se trasladó al ejemplar por una serie de soluciones de preservación:

- Primera solución: $12.5 \mathrm{ml}$ de $\mathrm{KOH} 0.5 \%+37.5 \mathrm{ml}$ glicerina, por un periodo de dos horas.

- Segunda solución: $25 \mathrm{ml}$ de $\mathrm{KOH} 0.5 \%+25 \mathrm{ml}$ glicerina, por un periodo de una hora.

- Tercera solución: $37.5 \mathrm{ml}$ de KOH $0.5 \%+12.5 \mathrm{ml}$ glicerina, por un periodo de dos horas.

- Solución final: $20 \mathrm{ml}$ de glicerina al $100 \%$, periodo de tiempo indefinido (el ejemplar dura hasta 5 años preservado sin recambio de glicerina).

\subsection{Costos totales}

Los costos de los materiales utilizados en la técnica de diafanización son distintos, de acuerdo al país o región.

Los costos específicos y generales del proceso para Hidalgo (México) se desglosan de la siguiente manera:

Tabla 1. Costos de la técnica de diafanización con tinción de Piovesana (2014), para un ejemplar (pez monja) menor de 4 centímetros, en pesos 
mexicanos. Datos obtenidos a partir de un promedio de tres proveedores de reactivos químicos.

\begin{tabular}{|c|c|c|c|}
\hline Fase & Reactivo & Cantidad & Costos \\
\hline Primera & Alcohol 70\% & $25 \mathrm{ml}$ & $\begin{array}{c}\$ 3.00 \\
(\mathrm{MXN})\end{array}$ \\
\hline Segunda & Agua destilada & $100 \mathrm{ml}$ & $\begin{array}{c}\$ 1.05 \\
(\mathrm{MXN})\end{array}$ \\
\hline Tercera & $\begin{array}{c}\text { Agua destilada / Hidróxido } \\
\text { de Potasio / Alizarina }\end{array}$ & $\begin{array}{c}100 \mathrm{ml} / \\
0.5 \mathrm{gr} / 0.8 \\
\mathrm{gr}\end{array}$ & $\begin{array}{c}\$ 1.08 \\
(\mathrm{MXN})\end{array}$ \\
\hline Cuarta & Solución de Mall & $100 \mathrm{ml}$ & $\begin{array}{c}\$ 4.31 \\
(\mathrm{MXN}) \\
\end{array}$ \\
\hline \multirow[t]{2}{*}{ Quinta } & $\begin{array}{c}\text { Agua destilada / Hidróxido } \\
\text { de Potasio / Glicerina }\end{array}$ & $\begin{array}{c}75 \mathrm{ml} / \\
0.375 \mathrm{gr} / \\
100 \mathrm{ml}\end{array}$ & $\begin{array}{l}\$ 17.81 \\
(\mathrm{MXN})\end{array}$ \\
\hline & & Total & $\begin{array}{l}\$ 27.25 \\
(\mathrm{MXN})\end{array}$ \\
\hline
\end{tabular}

Tabla 2: Costos generales de los reactivos en presentaciones comerciales. Promedio de tres proveedores de reactivos químicos.

\begin{tabular}{c|c|c}
\hline Reactivo & Cantidad & Precio \\
\hline Alcohol $70 \%$ & $500 \mathrm{ml}$ & $\$ 60.00(\mathrm{MXN})$ \\
\hline Agua destilada & $20 \mathrm{~L}$ & $\$ 210.00(\mathrm{MXN})$ \\
\hline Hidróxido de potasio & $25 \mathrm{~kg}$ & $\$ 1,500.00(\mathrm{MXN})$ \\
\hline Rojo de Alizarina & $100 \mathrm{gr}$ & $\$ 2,408.00(\mathrm{MXN})$ \\
\hline Glicerina & $1 \mathrm{~L}$ & $\$ 170.00(\mathrm{MXN})$ \\
\hline Agua oxigenada & $480 \mathrm{ml}$ & $\$ 18.00(\mathrm{MXN})$ \\
\hline & Total & $\$ 4,366(\mathrm{MXN})$ \\
\cline { 2 - 3 }
\end{tabular}

\section{Producto final}

Los resultados obtenidos del protocolo previamente mencionado, permiten visualizar, el tejido óseo que se tiñó de color rojo-morado, resaltando así los huesos del cráneo, la espina dorsal y los radios de las aletas caudal, dorsal, anal y lateral. Asimismo, es posible observar algunos órganos internos, incluyendo vejiga natatoria, corazón, hígado y cerebro, los cuales se aprecian de color pardo (Figura 8).

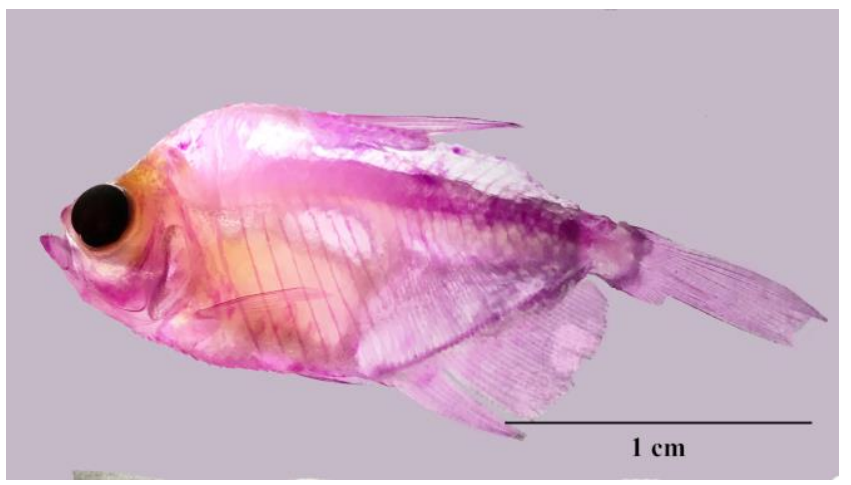

Figura 8. Gymnocorymbus ternetzi al término de la quinta fase.

\section{Discusión}

El método de Piovesana (2014), tiene nueve fases marcadas: fijación, transferencia, coloración, limpieza, neutralización, maceración, tinción, transparentación y preservación. El método propuesto en este artículo solamente consta de cuatro fases, sin contar la eutanasia, debido a que se omitió la coloración del tejido cartilaginoso con azul de alcián y a que se eliminó la fase de fijación con formol.

Para llevar a cabo el primer protocolo de Piovesana (2014), se requieren de 20 a 25 días aproximadamente, en contraste para el protocolo propuesto en este artículo se requiere un periodo de tiempo de 7 a 8 días.

Lo anterior debido a que se omite la fase de fijación con formol tamponado al $10 \%$, comenzando el proceso con la inmersión del ejemplar en alcohol al 70\%. Se excluyen las fases de coloración cartilaginosa, limpieza y neutralización, para proceder con la maceración del ejemplar en hidróxido de potasio al $2 \%$.

Posteriormente se tiñe la muestra con rojo de alizarina para después sumergirla en la solución transparentadora de Mall, la cual fue modificada. La original contiene: $79 \mathrm{ml}$ de agua destilada $+20 \mathrm{ml}$ de glicerina $+1 \mathrm{~g}$ de $\mathrm{KOH}+50 \mu \mathrm{lde} \mathrm{H}_{2} \mathrm{O}_{2} \mathrm{y}$ la modificada: $40 \mathrm{ml}$ de agua destilada $+12 \mathrm{ml}$ de glicerina + $500 \mathrm{mg}$ de hidróxido de potasio $(\mathrm{KOH})+1 \mathrm{ml} \mathrm{H}_{2} \mathrm{O}_{2}$.

Las ventajas de este nuevo protocolo son: la reducción de materiales y por lo tanto los costos, así como la fácil preparación de los reactivos, ya que se descartan instrumentos capaces de medir cantidades de volumen micrométricas.

Otro aspecto resaltable es la omisión de la descamación mecánica del ejemplar, lo cual conserva en mejor estado sus tejidos.

La última fase resulta opcional, ya que el ejemplar se encuentra completamente diafanizado y teñido; sin embargo, la sustitución paulatina del recambio de glicerina, da soporte a los tejidos, evitando así el daño de los mismos.

\section{Conclusiones}

La técnica de diafanización con tinción de Piovesana (2014) resulta de bajo costo por organismo trabajado. Siendo los reactivos más caros del proceso el hidróxido de potasio $(\mathrm{KOH})$ y el rojo de Alizarina.

Este protocolo para teñir tejido óseo está diseñado para organismos menores de $4 \mathrm{~cm}$, ya que entre mayor sea el organismo, mayor debe ser la concentración y/o el tiempo de preparación. 
El espécimen que se diafanizó presentó daños en la aleta caudal debido a la manipulación del mismo, ya que el hidróxido de potasio $(\mathrm{KOH})$ es altamente corrosivo, por ende, debilita los tejidos. Se recomienda manipular al organismo con precaución, evitando tomarlo por las aletas.

Son diversas las aplicaciones de esta técnica. En pruebas toxicológicas se emplea con el fin de buscar malformaciones congénitas. En embriología para observar en las distintas etapas del desarrollo los centros de osificación. Incluso dentro de la odontología tiene aplicaciones con el fin de estudiar los conductos radiculares. Asimismo, es útil y de bajo costo para elaborar colecciones de docencia e investigación.

\section{English summary}

\section{Optimization of the diaphonization and staining technique of Piovesana (2014), applied to the fish Gymnocorymbus ternetzi}

\begin{abstract}
The diaphonization technique consists in making the soft tissues of an organism transparent in order to observe the bone and cartilaginous tissues. Specific dyes are used for these purposes, mainly red alizarin for bone. There are no standardized protocols for each species, since it is generalized for large groups, being the group of fishes one of the least defined. In this article a protocol of the technique was developed for the nun fish (Gymnocorymbus ternetzi), there are included, the necessary chemicals, and the costs in Mexican pesos.
\end{abstract}

Keywords:

Diaphonization, alizarin red, Gymnocorymbus ternetzi.

\section{Agradecimientos}

A Martha Hernández Delgadillo por sus sugerencias realizadas en el desarrollo de la investigación.

\section{Referencias bibliográficas}

Burnett, A.R., \& Thomson, R.H. 1968. Phytochemestry. 7, 1421.

Concha, I. 2006. Diafanizacion. Universidad Santo Tomas: Unidad de Anatomia veterinaria. Recuperado de www.anato.cl/global/9tecanatomicas/diaf/9Agd0001.pp

Coronado C. 2014. Elaboración de material docente mediante la técnica de diafanización para la enseñanza de la morfogénesis ósea. Bgotá, Cundinamarca: Universidad nacional de Colombia.

Cortez-Delgado N, Pérez-Torres J, Hoyos JM. 2009. Staining procedure of cartilage and skeleton in adult bats and rodents. Int $\mathrm{J}$ Morphol: 27(4):1163-7.

Dawson A. A. 1926. Note on the staining of the skeleton of cleared specimens with Alizarin Red S. Biotechnology \& Histochemistry; 1, 123-124.

Inouye M. 1976. Differential staining of cartilage and bone in fetal mouse skeleton by alcian blue and alizarin red. Congenit Anom (Kyoto). 16:171-3.

Kiernan, J.A. 1990. Histological and histochemical methods. Theory and practice. Kiernan, J.A. (ed.). Second edition. Pergamon Press: Oxford. 433 pp.

Mall, F. P. 1902. On ossification centers in human embryos less than one hundred days old. American Journal of Anatomy. 5, 435-458.

Mc Green. 1952. A rapid method for clearing and staining specimens for the demonstration of bone. Ohio Journal of Science. 52(1):31-3.

McLeod MJ. 1980. Differential staining of cartilage and bone in whole mount fetuses by Alcian blue and alizarin red S. Teratology. 22:299301.

Piovesana, et al. 2014. Diafanización: Una técnica que permite la visualización diferencial de cartílago y hueso para el estudio del desarrollo y malformaciones en peces. Revista de la Sociedad Argentina de Histocenología, Vol. 25, 10:14 pp.

Randle AD. 1969. Automation of skeletal staining in the evaluation of teratogenicity. Laboratory Animals. 3:197-205.

Rivera-Cardona Guillermo. (2015). Técnica de diafanización con alizarina para el estudio del desarrollo óseo. Revista Colombiana Salud Libre, 10 (2), 109-115.

Taylor, W.R., Van Dyke, G.C. 1985. Revised procedures for staining and clearing small fishes and other vertebrates for bone and cartilage study. Cybium 9, 107-119.

Tilotta F, L. B.(2009. A study of the vascularization of the auricle by dissection and diaphanization. Surgical And Radiologic Anatomy 31:259-265.

Tipton PW, Burt ME. 1977. A method for mechanized staining of rat and mouse fetuses for teratological examination. Laboratory Animals. 11(4):265-7.

Villegas, A. C., Quiroga, M. D., \& Cleves, D. 2012. Diafanizacion: visualización del desarrollo óseo en fetos. Recuperado de http://www.pdfio.com/k-3611418.html

Webb GN, Byrd RA.1994. Simultaneous differential staining of cartilage and bone in rodent fetuses: an Alcian blue and alizarin red $S$ procedure without glacial acetic acid. Biotechnol Histochem. 69:181-5.

Whitaker J, Dix KM. 1979. Double staining technique for rat fetus skeletons in teratological studies. Lab Anim. 13:309-10. 